\title{
NOTAS SOBRE UN RETRATO DEL OBISPO VICENTE ROMÁN Y LINARES, OBRA DE JOSÉ DOMÍNGUEZ BÉCQUER
}

\author{
NOTES ABOUT A PORTRAIT OF BISHOP \\ VICENTE ROMÁN Y LINARES, PAINTED BY \\ JOSÉ DOMÍNGUEZ BÉCQUER
}

\author{
Juan Alejandro Lorenzo Lima \\ Universidad Europea de Canarias. España \\ juanalejandro.lorenzo@universidadeuropea.es
}

\begin{abstract}
El hallazgo de la documentación que pormenoriza el encargo de un retrato del obispo Vicente Román y Linares (1767-1835) anima a estudiar dicha obra con nuevos argumentos. Para ello es necesario contextualizar su ejecución en la década de 1830 y hacerla coincidir con un proceso de renovación que impulsaban los canónigos de La Laguna, demandantes y promotores de tan "solemne efigie". El material investigado confirma que es obra del pintor romántico José Domínguez Bécquer (1805-1841), cuya dedicación a la retratística es igualmente resaltada.

Palabras clave: Vicente Román y Linares; José Domínguez Bécquer; Romanticismo; Sevilla; La Laguna.
\end{abstract}

The discovery of documentation reporting the commission of a portrait of Bishop Vicente Román y Linares (1767-1835) let its study with new approach. This requires to contextualize its execution in the 1830 s and linking it to a renewal plan promoted by the canons of La Laguna, their plaintiffs. Files notes confirm that it is a work by the romantic painter José Domínguez Bécquer (1805-1841), whose dedication to the portrait is also highlighted.

Keywords: Vicente Román y Linares; José Domínguez Bécquer; Romanticism; Seville; La Laguna.

\section{INTRODUCCIÓN}

Perpetuar el recuerdo de cualquier personaje notable ha sido una aspiración desde la más remota Antigüedad, hasta el punto de que tal coyuntura posibilitó la 
ejecución de retratos con fines e intereses muy diversos. En base a esa disyuntiva, el alto número de efigies o representaciones que se contrataron durante las épocas Moderna y Contemporánea testimonia usos, alcances y significados de distinto alcance, no resultando fácil su análisis e interpretación bajo presupuestos genéricos ${ }^{1}$. Existen tantos retratos como intenciones y objetivos se esconden tras ellos, de modo que comprender casuísticas tan diferentes es un reto para quien los analiza con afán testimonial o contextualizador ${ }^{2}$; y por si fuera poco, las dificultades aumentan a raíz de que el siglo XIX otorgara al género mayor éxito y una variedad tipológica desconocida hasta el momento. El avance que la retratística mostró a partir de entonces como manifestación autónoma posibilitaría en gran medida ese fenómeno ${ }^{3}$, pero a ello tampoco fueron ajenas las transformaciones sociopolíticas que trajo consigo la crisis del Antiguo Régimen y el influjo del ideario burgués, capaz de reinventar modismos aducidos una y otra vez en las centurias precedentes ${ }^{4}$.

En esta ocasión centraremos el análisis en un retrato de Vicente Román y Linares (1767-1835), a quien cupo el honor de ser obispo auxiliar de Tenerife e instituir la diócesis nivariense en diciembre de $1819^{5}$. Antes de ese acontecimiento se había revelado como un hombre caritativo y ejemplar por su virtud, fraile premostratense de larga trayectoria, intelectual de reconocidas aptitudes y predicador del rey Carlos IV, algo en lo que insistían los elogios fúnebres que amigos e instituciones eclesiásticas publicaron al tiempo de su muerte en Sevilla y La Laguna ${ }^{6}$. Sin embargo, como estudiamos en otra ocasión, la biografía de un personaje del talante de Román trasciende a esos hechos y se convierte en testimonio de las dificultades que atravesó entonces la Iglesia española, cuyo futuro inmediato no pudo sustraerse al descalabro procurado por la Guerra de la

${ }^{1}$ Cfr. AA. VV.: El retrato. Madrid, 2004.

2 Así lo puso de relieve en fecha temprana una publicación de GLENDINNING, Nigel: Goya. La década de los Caprichos. Retratos 1792-1804. Madrid, 1992.

3 DÍEZ, José Luis: "El retrato español del siglo XIX", en El retrato. Madrid, 2004, pp. 311-340.

${ }^{4}$ MOLINA, Álvaro: Mujeres y hombres en la España ilustrada. Identidad, género y visualidad. Madrid, 2013.

${ }^{5}$ NAVARRO MEDEROS, Miguel Ángel: Antecedentes, creación y comienzos de la diócesis de San Cristóbal de La Laguna. Islas Canarias, 2004, con bibliografía previa.

${ }^{6}$ GARCÍA BLANCO, Antonio María: Oración fúnebre que en las solemnes exequias del Illmo. Sr. D. Vicente de Román y Linares, obispo de Dan-Sara, dijo (presente el Emmo. Sr. cardenal arzobispo) el lic. D. Antonio María García Blanco, magistral de la Santa y Real Capilla de San Fernando, el día 11 de abril de este año en la Iglesia Parroquial del Sagrario. Sevilla, 1835; y PEREIRA PACHECO Y RUIZ, Antonio: Oración fúnebre que en las solemnes exequias del Illmo. Sr. D. Vicente Román y Linares, obispo de Dan-Sara, auxiliar de las Islas Canarias y comisionado apostólico y regio para la erección de la catedral de San Cristóbal de La Laguna de Tenerife, últimamente auxiliar de Sevilla. La Laguna, 1835. 
Independencia, una crisis vocacional que afectó a toda clase de monasterios, el laicismo latente y, sobre todo, la disputa que liberales y absolutistas sostuvieron durante el reinado de Fernando VII $^{7}$.

Enfermo y achacoso, a raíz de la elección de Luis Folgueras (1769-1850) como primer obispo de Tenerife en abril de 1824, Román y Linares solicitó traslado a la Península, donde aspiraba a residir durante los últimos años de su vida y no convertirse en titular de otra diócesis u organismo eclesiástico. Tal fue así que acabaría residiendo en Sevilla con la dignidad de obispo de Dan Sara, hasta el punto de que los órganos gubernamentales reconocieron de modo oficial el auxilio que prestaba al entonces arzobispo de la ciudad Francisco Javier Cienfuegos y Jovellanos (1766-1847) ${ }^{8}$. A pesar de lo manifestado a veces por él mismo, durante los últimos años de su vida atendió labores episcopales ${ }^{9}$ y, en febrero de 1829 , fue nombrado presidente del sínodo que tenía lugar entonces. A ello cabe sumar el cargo que desempeñó de visitador en los monasterios y beaterios que estuvieron sujetos al arzobispado, "cuyo destino tal vez aceleró los preciosos días de su vida, pues -como recuerdan los biógrafos- recto en todo era enemigo de chismes y de bagatelas". García Blanco le ayudó en el desempeño de esa tarea entre octubre y noviembre de 1834, siendo testigo directo de "su docilidad y amor a los demás, de una dulzura natural y de una afabilidad que se manifestaba sin ficción"10.

Entretenido con estos quehaceres diarios y con cultos que atendía habitualmente en la catedral y en iglesias del centro urbano, Vicente Román y Linares falleció en Sevilla el 29 de marzo de 1835 por "una calentura apoplética que duró cinco días" y lo mantuvo recluido en su domicilio de la calle Alcázares. Los funerales previstos en honor suyo revistieron cierta solemnidad y, como exponen algunas crónicas de la época, concluyeron con la sepultura del cadáver en una capilla catedralicia de la Virgen de la Estrella donde oraba con frecuencia ${ }^{11}$.

Durante los años de residencia en Sevilla tuvo lugar el encargo, la ejecución y el pago del retrato que nos ocupa, obra documentada al pintor José María Domínguez Bécquer (1805-1841) que no resulta conocida ni apreciada fuera del

${ }^{7}$ LORENZO LIMA, Juan Alejandro: "Apuntes para una biografía del obispo Vicente Román y Linares (1767-1835), instaurador de la diócesis nivariense", Estudios Canarios. Anuario del Instituto de Estudios Canarios, LVIII, 2014, pp. 303-334.

${ }^{8}$ ROS, Carlos: Historia de la Iglesia de Sevilla. Sevilla, 1992, pp. 843-844.

${ }^{9}$ Entre ellas la ordenación de clérigos, algo que desembocó en una disputa notable por su afán de instruir adecuadamente a los postulantes. Así sucedió, por ejemplo, con Francisco de Paula Páez y Rivero, quien optaba al subdiaconado en abril de 1830. La abundante correspondencia que motivó tal suceso y sus consecuencias se conserva en la Biblioteca Universitaria de La Laguna (B.U.L.L.), Fondo Antiguo, Ms. 84, ff. 39r-66r.

${ }^{10}$ GARCÍA BLANCO, A. M.: Oración..., op. cit., pp. 10 y 17.

11 VELÁZQUEZ SÁNCHEZ, José: Anales de Sevilla. Reseña histórica de los sucesos políticos, hechos notables y particulares intereses de la tercera capital de la monarquía, metrópoli andaluza, de 1800 a 1850. Sevilla, 1872, pp. 432-433. 
ámbito insular (Figura 1). Alusiones previas en algunas publicaciones de Tenerife $^{12}$ y un comentario breve en el último volumen dedicado al patrimonio catedralicio de La Laguna ${ }^{13}$ ponen de relieve la significación de tan "solemne efigie", cuyo análisis es posible ahora gracias a noticias, acuerdos plenarios y apuntes en la correspondencia que describen pormenorizadamente su contratación y posterior envío hasta el Archipiélago. Esa abundante documentación, inédita hasta el momento, nos anima a publicar el presente artículo, advirtiendo de entrada el protagonismo que el clérigo Antonio Pereira Pacheco y Ruiz (1790-1858) tuvo en dichos trámites y en la reorganización del organismo capitular después de $1828^{14}$.

Al prebendado Pacheco, uno de los individuos más diligentes que tuvo la diócesis nivariense e impulsor del cabildo eclesiástico hasta el tiempo de su retiro voluntario en Tegueste, se debe el contacto previo con Román y una relación epistolar que trasciende a la encomienda recibida para ajustar la pintura que trata$\operatorname{mos}^{15}$. Sin embargo, como acontece siempre, la intrahistoria del retrato comenzó mucho antes y sin que llegaran a imaginarlo los responsables de su ejecución. Pacheco conoció al futuro prelado de Tenerife durante un periodo de reclusión en Cádiz, al tiempo que Román y Linares residía allí huyendo de la Guerra de la Independencia y él esperaba navío para embarcar hacia Perú y formar parte de la comitiva del ya obispo de Arequipa, Luis de la Encina (1754-1816). Luego, a raíz de su regreso a Canarias con motivo de la instauración diocesana de 1819, retomaron una amistad que se antojó beneficiosa para ambas partes. Román recurrió a él para comunicar toda clase de asuntos al cabildo y el prebendado respaldaría siempre al sufrido obispo, quien no tuvo un apoyo unánime a la hora de dividir la diócesis del Archipiélago y determinar los privilegios eclesiásticos ${ }^{16}$. Por ese motivo, como colaborador y aliado suyo, Pacheco escribió la oración fúnebre que fue leída en la catedral de La Laguna el 6 julio de 1836, impresa luego para perpetuar la memoria de quien había sido un "religioso ejemplar y el mejor amigo de todos"17.

${ }^{12}$ HERNÁNDEZ PERERA, Jesús: Cincuentenario de la Catedral de La Laguna. La Laguna, 1963, pp. 18-19, nº 27; y HERNÁNDEZ DÍAZ, Patricio: Pinturas de la Catedral de La Laguna. La Laguna, 1984, pp. 83-84.

${ }^{13}$ LORENZO LIMA, Juan Alejandro: "Retrato del obispo Vicente Román y Linares", en Patrimonio e historia de la Catedral de La Laguna. La Laguna, 2013, p. 119, nº III.7.

${ }_{14}$ Últimas valoraciones sobre este personaje en LORENZO LIMA, Juan Alejandro y HERNÁNDEZ GONZÁLEZ, Manuel Jesús: Pereira Pacheco, párroco de Tegueste. Tegueste, 2016.

${ }^{15}$ Cfr. GONZÁleZ YANES, Emma: El prebendado Don Antonio Pereira Pacheco. La Laguna, 2002.

16 NAVARRO MEDEROS, M. Á.: Antecedentes..., op. cit., pp. 213-220.

17 PEREIRA PACHECO Y RUIZ, A.: Oración fúnebre..., op. cit., p. 12. 
Como ya se ha comentado, la ejecución de la obra en Sevilla está justificada por la residencia permanente de Román y Linares en esa ciudad. Al igual que en épocas posteriores, Andalucía fue una región a la que viajaron ocasionalmente los miembros del cabildo ${ }^{18} \mathrm{y}$ allí sus contactos no permanecerían al margen de cuantas peticiones elevaban los capitulares de La Laguna. Lo interesante es que no siempre se cumplieron sus expectativas, aunque de ellas hay al menos constancia documental. No en vano, sabemos que el deán y sus compañeros ambicionaron entonces la compra de alfombras, varias piezas de plata, crucifijos de metal para los altares, libros litúrgicos, el tornavoz del púlpito y una "imagen de Cristo muerto en la Cruz" que iba a presidir el aula capitular. Intuimos que para la última entablaron contacto con el ya "famoso escultor" Juan de Astorga (17791849), pero el alto precio de su trabajo y los costes adicionales del transporte determinarían que dicha efigie fuera encomendada antes de 1828 al maestro local Fernando Estévez (1788-1854) ${ }^{19}$.

Esta preponderancia de la vía andaluza se vio posibilitada por la residencia en Sevilla del lagunero Cristóbal Bencomo (1758-1835), confesor de Fernando VII y encumbrado arzobispo de Heraclea, cuya gestión sería decisiva a la hora de crear la diócesis en 1819. No debe olvidarse que dicho eclesiástico tuteló en la distancia el amueblamiento de la nueva catedral y que antes de su muerte remitió desde esa ciudad obras tan diversas como dos relicarios de plata, libros de temática religiosa, tejidos, papel para los documentos oficiales, ornamentos menores o de tela blanca para el diario, sus ricos pontificales, botijas de aceite, vasos sagrados y, muy especialmente, la baranda de hierro que delimitó al principio la vía sacra y había contratado el maestro de la seo hispalense Rafael Ibáñez, cuyo montaje provisional en la plaza de la Maestranza para la contemplación del arzobispo y otros eclesiásticos llamó la atención de tantos contemporáneos ${ }^{20}$. Asimismo, su contacto reiterado con el pintor Antonio de Quesada (con actividad

${ }^{18}$ Entre ellos el propio Pacheco, quien residió en Sevilla varios meses entre 1837 y 1838 para defender el mantenimiento de la joven diócesis de Tenerife, entonces en sede vacante. De ese tiempo data una correspondencia de gran interés, no publicada hasta ahora, y algunos manuscritos que convendría localizar y estudiar en el futuro por su alta significación histórica, entre ellos Observaciones sobre el ceremonial de la Catedral de Sevilla. GONZÁLEZ YANES, E.: El prebendado..., op. cit., p. 79.

${ }^{19}$ LORENZO LIMA, Juan Alejandro: "De una escultura con apacibilidad, dulzura y majestad. Fernando Estévez y el Cristo de las salas capitulares", en Actas de las V jornadas Prebendado Pacheco de investigación histórica. Tegueste, 2013, pp. 267-309, con bibliografía previa.

${ }^{20}$ DARIAS PRÍNCIPE, Alberto y PURRIÑOS CORBELLA, Teresa: Arte, religión y sociedad. La Catedral de La Laguna. La Laguna, 1997, pp. 159-160. Para contextualizar estas medidas resulta oportuna la lectura de LORENZO LIMA, J. A.: "La diócesis y su catedral. El edificio, los equipamientos y el nuevo patrimonio", en Patrimonio..., op. cit., pp. 136-145, n' III.12. 
conocida entre 1815 y 1839) permitió que dicho artífice diera acabadas al menos tres pinturas de gran tamaño donde quedaron representados San Cristóbal, San Fernando y Santa Isabel, patronos de la diócesis que presidieron altares propios en el templo ${ }^{21}$. De alguna u otra forma, el envío del retrato de Domínguez Bécquer dio continuidad a esta dinámica de encargos y puso de relieve el protagonismo que los obradores andaluces -y preferentemente los sevillanos, imbuidos ya de sensibilidad romántica- tuvieron a la hora de incrementar el patrimonio catedralicio de La Laguna.

\section{UN RETRATO COMO TESTIMONIO DE GRATITUD}

El apego que los fieles y el cabildo eclesiástico de La Laguna sintieron hacia Vicente Román y Linares quedó de manifiesto en documentos redactados después de su marcha a Sevilla en 1824, aunque posee un testimonio ineludible en ciertos obsequios que le hicieron antes de ello ${ }^{22}$ y en la voluntad de contar con una representación suya para incrementar la galería de retratos que fue habilitada en el aula capitular desde 1819. Dicha colección de obras pretendía homenajear a los promotores y varones más instruidos del nuevo obispado, emulando con su instauración una costumbre iniciada en catedrales españolas a partir del siglo XVI. Ya en 1820 se tomó la determinación de pagar al pintor Luis de la Cruz y Ríos (1776-1853) 2.000 reales por los retratos que había concluido en Madrid del rey Fernando VII y de Cristóbal Bencomo, cumpliendo así "las más apetecibles esperanzas de la nueva diócesis" 23 (Figuras 2-3). Al soberano y al encumbrado arzobispo de Heraclea, su confesor ya citado, se debió la diócesis en una época cambiante para la política religiosa, por lo que resulta comprensible que el ideario común de tintes absolutistas alentara esa empresa y otras del mismo tipo que no pudieron materializarse en la catedral por falta de fondos ${ }^{24}$.

En ese contexto, siendo conscientes del protagonismo que habían alcanzado como colectivo religioso e institucional, los capitulares no desaprovecharon la ocasión de exaltar su historia y el recuerdo de cuantos sujetos la hicieron posible en un tiempo tan convulso. Así, a los primeros testimonios llegados de Madrid

${ }^{21}$ CONCEPCIÓN RODRÍGUEZ, J.: "San Cristóbal, San Fernando y Santa Isabel de Portugal", en Patrimonio..., op. cit., pp. 117-118, n III.6, con bibliografía precedente.

${ }^{22}$ Entre otros unas vinajeras de plata que el orfebre Ventura Correa concluyó en 1820 y llevaría consigo a Sevilla, conocidas ahora por el diseño que reprodujo Pacheco. HERNÁNDEZ PERERA, Jesús: "Dibujos de platería de Pereira Pacheco". Estudios Canarios. Anuario del Instituto de Estudios Canarios, XXXIX, 1995, p. 47, dibujo 10.

${ }_{23}$ Archivo Catedral de La Laguna (A.C.L.L.): Libro I de actas capitulares, f. 122. Cit. HERNÁNDEZ DÍAZ, P.: Pinturas..., op. cit., pp. 67-71.

${ }^{24}$ LORENZO LIMA, J. A.: "Primeros retratos del aula capitular", en Patrimonio..., op. cit., pp. 115-116, $\mathrm{n}^{\circ}$ III.3. 
siguió la adquisición de al menos dos retratos más donde el pintor local Juan de Abreu (1800-1877) reprodujo en 1829-1830 y 1832-1833 los rasgos fisonómicos de Pedro José Bencomo (1750-1828) y Alonso de Nava (1757-1832), deán y VI marqués de Villanueva del Prado respectivamente ${ }^{25}$. Lo interesante del último encargo es que para su ejecución se comisionó al prebendado Pacheco, quien, como advierten las actas capitulares, tenía libertad para ejecutar "sendas efigies bien aquí [entiéndase Tenerife], o bien en España"26.

De acuerdo a esos antecedentes, el retrato de Vicente Román y Linares que estudiamos sería la quinta incorporación a tan loable gabinete de retratos (Figura 1). Las primeras noticias que aluden a su contratación datan del verano de 1832, al tiempo en que los capitulares ajustaban el pago de la obra previa de Alonso de $\mathrm{Nava}^{27}$. Ya hay noticias sobre su adquisición en un acuerdo de noviembre de $1832^{28}$, pero, como era habitual en la época, dicha propuesta no fue atendida de inmediato ni obtuvo la prioridad que anhelaron canónigos afines al recuerdo de Román. Hubo que esperar al menos dos años más para que tal aspiración empezara a materializarse. El 12 de julio de 1834 los regentes del cabildo eclesiástico comunicaban a Antonio Pacheco la necesidad de contratar la obra en Sevilla, porque, según le informó su secretario, era el lugar donde podía adquirirse sin complicaciones y donde Román iba a residir de forma permanente durante los próximos meses. Lo atractivo del trámite es que los canónigos laguneros le concedieron potestad para que él mismo escribiera al prelado informándole sobre el tema, con el fin de que "a su gusto elija allí el pintor que sea de su satisfacción" 29.

Los capitulares comunicaron a Pacheco varias condiciones que debía acomodar la obra, con el propósito de que "el tamaño del lienzo sea de la medida de alto y ancho que V[uestra] S[eñoría] hará el favor de enviarle con arreglo a los que adornan nuestra sala, [y] que al pie del retrato se deje el espacio conveniente para poner la inscripción que ha de acompañar a la medida, de un color proporcionado a lo visible del retrato". Le informaban también sobre su composición idónea, ya que todos convinieron en que la nueva representación diese cabida a "una mesa sobre la cual [...] figure el Real Decreto Auxiliatorio de erección de esta Santa Iglesia con letras legibles que lo demuestre, y en la mano de la imagen del referido Señor Obispo de Dan-Sara la Bula de su Santidad para la fundación de

${ }^{25}$ HERNÁNDEZ PERERA, J.: Cincuentenario..., op. cit., p. 20; y HERNÁNDEZ DÍAZ, P.: Pinturas..., op. cit, pp. 76-79.

26 A.C.L.L., Libro VII de actas capitulares, f. 95v (junta de 9-12-1832).

${ }^{27}$ HERNÁNDEZ DÍAZ, P.: Pinturas..., op. cit., pp. 83-84.

28 A.C.L.L., Libro VII de actas capitulares, f. 95v (junta de 9-12-1832).

${ }_{29}$ B.U.L.L., Fondo Antiguo, Ms. 27-II, f. 91r. 
esta Iglesia". Esperaban, pues, que el modelo o en nombre suyo algún secretario expresaran "a este Cabildo el costo para remitirlo oportunamente" 30 .

Pacheco no tardó en cumplir con su cometido, de modo que el 30 de julio escribía una carta al obispo Román informándole sobre el proyecto y la finalidad del cuadro que pensaba adquirir el colectivo capitular. De ahí que no viese inconveniente para que "dignara prestarse a ello, pues -explica el mismo prebendado en una primera misiva - al intento escribo al Señor Don Juan [José García, su sobrino y asistente] para que hecha por V[uestra] S[eñoría] I[lustrísima] la elección de pintor, intervenga aquél en los costos de su ejecución y me lo avise para no perder momento en ponerlos en su mano". Le avisó igualmente sobre el texto que debía figurar en la inscripción dispuesta al pie de la efigie, advirtiendo que él mismo podía "añadirle o quitarle lo que sea de su agrado" 31 . No es casual, por lo tanto, que ese día Pacheco remitiera un oficio a García comunicándole las mismas cuestiones ${ }^{32}$.

En La Laguna no tuvieron respuesta sobre esa y otra misiva del secretario capitular hasta diciembre de 1834, ya que el día 14 el propio Román expresaba a los canónigos su complacencia con tantas "demostraciones de respeto y amor" que le habían manifestado desde la institución del cabildo en 1819. Informó entonces que "estoy pronto a darle gusto, a pesar de la repugnancia que siempre he tenido a prestarme [a posar o a ser retratado]", a la vez que invocaba un sentimiento de gratitud "por el que - explica sin tapujos- viviré agradecido y corresponderé gustoso en todo tiempo" 33 . A pesar de que no lo mencione de un modo claro, suponemos que el ya obispo de Dan Sara agradecía la atención que los capitulares laguneros le brindaban en forma de pensión o renta vitalicia por acuerdo de la superioridad eclesiástica y los órganos gubernamentales del reino. No obstante, es probable que nunca supiera o imaginase que dichos conocidos y amigos cuestionaron en más de una ocasión tal dádiva, habida cuenta de que suponía un gasto importante para la economía de una diócesis nueva y pobre como la nivariense ${ }^{34}$.

Sin tiempo que perder, Juan José García envió carta a Antonio Pereira en diciembre de 1834 contándole los avances que había realizado a propósito del retrato. De la misiva se deduce que el maestro elegido por él y el propio Román fue siempre José Domínguez Bécquer, a pesar de que no residía temporalmente en la ciudad de Sevilla por cuestiones laborales. Advirtió entonces que "el pintor [...] señalado para la obra es de lo mejor, mas hallándose en Madrid expresó

${ }^{30}$ B.U.L.L., Fondo Antiguo, Ms. 27-II, f. 91r, aunque el acuerdo previo es descrito en A.C.L.L., Libro VIII de actas capitulares, ff. 51r-51v (junta de 14-6-1834).

${ }^{31}$ B.U.L.L., Fondo Antiguo, Ms. 27-II, ff. 92r-93r.

32 B.U.L.L., Fondo Antiguo, Ms. 27-II, f. 94r.

${ }_{33}$ B.U.L.L., Fondo Antiguo, Ms. 27-II, f. 97r.

${ }^{34}$ LORENZO LIMA, J. A.: "El cabildo eclesiástico y los patricios diocesanos", en Patrimonio..., op. cit., pp. 102-109, nº III.1. 
aguardará que venga, y tan luego como se verifique sabrá cuanto es el costo que ha de tener el retrato y entonces se lo diré a V[sted] según [...] me prevenga" ${ }^{35}$. Más tarde, el 22 de enero de 1835, escribió de nuevo expresándole que había iniciado los trámites para garantizar la ansiada ejecución del retrato ${ }^{36}$.

La contratación no revelaba ya excesivos problemas y así lo entendieron los canónigos tinerfeños, quienes el 26 de enero de 1835 mandaron otra carta a Román dándole las gracias por "condescender a su entrañable y tierna solicitud", al tiempo que esperaban "la mas lisonjera confianza en que las circunstancias propensas faciliten cuanto antes el logro de nuestro constante deseo" ${ }^{37}$. Igual agradecimiento manifestaron el mismo día a Pacheco, quien mostró cautela respecto a la demora de una negociación que era tan factible en Sevilla como en La Laguna ${ }^{38}$.

El retrato debió pintarse entre los meses de febrero y junio de 1835, puesto que el 1 de julio, fallecido ya Román, Juan José García notificó a Pacheco que iba a remitirlo a Tenerife por medio de Santiago Montemayor. Le informaba también que la cuenta pormenorizada de los gastos debía conducirla un tal Manuel Hernández, quien podría comparecer ante él sin carta de presentación pero con el recibo correspondiente ${ }^{39}$. Gracias a dicho documento sabemos que el coste de la obra ascendió a un total de 1.110 reales, de los cuales 600 importarían los honorarios del pintor ${ }^{40}$, 146 el marco ensamblado y dorado en Sevilla, 140 el cajón con forro de hule que garantizaba su transporte y otros gastos menores que cubrieron hasta los herrajes para colgarlo en el aula capitular. A ello se une el resto de partidas que importó su traslado a Canarias, primero hasta Cádiz en carruaje, luego desde allí a Tenerife a bordo del vapor Betis, y finalmente, a través de la balandra Antoñita, procurar su desembarque en la rada santacrucera para subirlo hasta La Laguna por medio de un carretero de confianza ${ }^{41}$.

Al día siguiente, el 2 de julio de 1835, Pacheco informó sobre la obra a varios integrantes del cabildo, señalando que, como era preceptivo, el modelo se había figurado según la instrucción dada. Presentaba entonces una carta relativa a su envío, la cuenta pormenorizada y todo lo concerniente al trámite administrativo que había coordinado desde el año anterior junto a Juan José García. Restaba, pues, efectuar parte de los pagos. Por ese motivo pidió que la contaduría decimal comunicara al hacedor de La Palma, Miguel Monteverde, el gasto ocasionado

${ }^{35}$ B.U.L.L., Fondo Antiguo, Ms. 27-II, f. 95r-96v.

${ }^{36}$ B.U.L.L., Fondo Antiguo, Ms. 27-II, f. 97r.

${ }^{37}$ B.U.L.L., Fondo Antiguo, Ms. 18, f. 106r.

${ }_{38}$ B.U.L.L., Fondo Antiguo, Ms. 27-II, f. 98r.

39 B.U.L.L., Fondo Antiguo, Ms. 27-II, f. 99r.

${ }^{40}$ Cantidad ya señalada por HERNÁNDEZ DÍAZ, P.: Pinturas..., op. cit., p. 84.

${ }^{41}$ B.U.L.L., Fondo Antiguo, Ms. 27-II, f. 100r. Para un conocimiento de estas cuestiones, véase la transcripción de las cuentas o del balance de gastos que incluímos como apéndice documental. 
por la pintura y su traslado, ya que los canónigos eligieron dicha vía para suplirlo sin demora a los herederos de Román ${ }^{42}$. Cabe suponer que esas retribuciones se produjeron de inmediato, puesto que el 30 de julio, apenas una semana después de que el lienzo arribara a la isla, el prebendado escribió a García contándole lo sucedido hasta ese momento. Gracias a dicha misiva y al correspondiente acuerdo plenario sabemos que el retrato no sería presentado de modo oficial hasta una junta que tuvo lugar el 28 de julio, cuando fue colgado en la sala capitular con el beneplácito de los canónigos y otros clérigos que servían en la catedral ${ }^{43}$.

En palabras del secretario capitular, todos quedaron "satisfechos por la buena ejecución, dejando en esta parte llenos los deseos del Cabildo y del público”. El propio Pacheco participó de esos elogios, manifestando a título personal que "el pincel me ha complacido mucho, no obstante que por lo que hace á las semejanzas veo por el retrato que S[u] I[lustrísima] tuvo gran mudanza en su semblante de como estaba aquí; pero -apostilla- los que lo vieron ahí convienen unánimes en que se le parece bastante" 44 .

Concluía así el encargo del retrato de Román y Linares, aunque restaba la inclusión de inscripciones en la parte inferior del lienzo y de los anteriores para conferir unidad a la galería de patricios diocesanos. Por ese motivo, en abril de 1837 los canónigos comisionaron una vez más a Pacheco para resolver el asunto redactando él mismo las leyendas que "deben colocarse al pie de los retratos de los señores Bencomos que se hallan en la sala capitular" 45 . El prebendado cumplió de inmediato con su cometido, apuntando de paso que la relativa al lienzo que nos ocupa quedó estipulada del siguiente modo: “El Illmo. Sor. D ${ }^{\text {n }}$ Vicente Román y Linares, por la gracia de Dios y de la Santa Sede Apostólica Obispo de Dan=Sara in partibus infedilium, y Auxiliar de Tenerife en Canarias, del Consejo de S. M. y su Predicador, Teniente Vicario general de los $\mathrm{R}^{\mathrm{s}}$ Exercitos y Armada, Comisionado Apostólico y Regio para la división del Obispado de Canarias y erección del de San Cristobal de la Laguna en Tenerife, instaló esta Santa Iglesia y su Cabildo el día 21 de Diciembre de 1819"46.

\section{LA OBRA}

Después de su colocación en julio de 1835, el retrato de Román y Linares despertó interés entre quienes se ocuparon de él o tuvieron trato con el personaje

${ }^{42}$ B.U.L.L, Fondo Antiguo, Ms. 27-II, f. 101r.

${ }^{43}$ A.C.L.L., Libro VIII de actas capitulares, f. 191v (sesión de 31-7-1835).

${ }^{44}$ B.U.L.L., Fondo Antiguo, Ms. 27-II, f. 101r.

45 B.U.L.L., Fondo Antiguo, Ms. 27-II, ff. 104r-105v.

46 B.U.L.L., Fondo Antiguo, Ms. 27-II, ff. 104r-105v. Sin embargo, la contenida finalmente en el lienzo suprime algunos datos señalados por Pacheco. Así se deduce de lo transcrito con anterioridad por HERNÁNDEZ DÍAZ, P.: Pinturas..., op. cit., p. 83. 
efigiado antes de su marcha a Sevilla en 1824. Sin embargo, fue otra vez Pereira Pacheco quien en su Noticia histórica sobre la erección de la Santa Iglesia Catedral describía el ornato de la sala capitular, advirtiendo que en ella tuvieron cabida ricas colgaduras de damasco, mobiliario elaborado con esmero por carpinteros locales, un dosel de terciopelo, el Crucificado de Fernando Estévez que la presidía desde 1828, útiles muy diversos de escritura y la colección de retratos que trata$\operatorname{mos}^{47}$; entre ellos no olvidó el prebendado "la [efigie] del S[eño]r D[o]n Vicente Román y Linares [que] se hizo en Sevilla, pintada p[o]r D[o]n José D[omínguez] Becquer" ${ }^{\prime 4}$. Dicho apunte es de vital importancia al tratarse de la única vez en que los documentos refieren la identidad del artista elegido para su ejecución, ya que el lienzo no aparece firmado y el nombre del autor fue omitido de forma reiterada en los comprobantes o recibos de pago, en los acuerdos de las actas capitulares donde se alude al tema y en la correspondencia intercambiada a raíz de su contratación entre Sevilla y La Laguna ${ }^{49}$. No es casual que esa cita fuera indispensable para que Hernández Perera, Reyes Darias y Hernández Díaz lo mencionaran en sus trabajos de investigación con un criterio diverso ${ }^{50}$. Con todo, a pesar de la información contenida en otras publicaciones y de su exposición pública durante el año $2000^{51}$, resulta desconocido fuera de las Islas. No figura, por ejemplo, en el último catálogo o repertorio de obras que Rubio Jiménez publicó sobre el patriarca de los Bécquer en $2007^{52}$.

La omisión puede deberse al emplazamiento en Canarias y a su acabado, ya que el retrato de Vicente Román no deja de ser una obra convencional si atendemos a las cualidades que manifiesta. Responde a un encargo oficioso y condicionado por la voluntad de los comitentes, quienes, como ya sabemos, exigieron a su autor que incluyera en la composición una mesa y documentos que guardan relación con el personaje efigiado: el real decreto auxiliatorio y la bula fundacional de la diócesis (Figura 1). Ante tal coyuntura, las opciones no eran muchas y Domínguez Bécquer optó por reproducir las características que manifestaba cualquier retrato eclesiástico de ese periodo. De ahí que Román se presente en posición sedente, ataviado con vestimentas acordes a su dignidad episcopal y portando los

${ }^{47}$ Para un conocimiento de esta dependencia y del inmueble de las salas capitulares, la primera empresa rematada en el complejo catedralicio, véase DARIAS PRÍNCIPE, A. y PURRIÑOS CORBELLA, T.: Arte..., op. cit., pp. 184-189.

48 B.U.L.L., Fondo Antiguo, Ms. 27-I, f. 18v.

${ }^{49}$ LORENZO LIMA, J. A.: "Retrato del obispo Vicente Román y Linares", en Patrimonio..., p. 119, n $^{\circ}$ III.7.

${ }^{50}$ HERNÁNDEZ PERERA, J.: Cincuentenario..., op. cit., p. 18; REYES DARIAS, Alfredo: Las Canarias occidentales. Tenerife, La Palma, La Gomera, El Hierro. Barcelona, 1969, p. 214; y HERNÁNDEZ DÍAZ, P.: Pinturas..., op. cit., pp. 83-84.

${ }^{51}$ AA.VV.: La Catedral de La Laguna: su historia y patrimonio litúrgico. La Laguna, 2000, pp. 13-14.

${ }^{52}$ Cfr. RUBIO JIMÉNEZ, Jesús: José María Domínguez Bécquer. Sevilla, 2007. 
distintivos de ello, en este caso cruz pectoral al cuello y anillo en una de sus manos a juego, compuestos ambos con brillantes pequeños y pedrería fina de tonos naranjas. El aplomo que procura la imagen del prelado guarda relación con el mobiliario descrito a través de un elegante sillón de brazos, tapizado en rojo y con motivos de talla donde resultan perceptibles soluciones del ya común estilo Imperio. Los recursos ornamentales permitieron que en el remate de dicha pieza se incluyera su escudo armas, excusando así el protagonismo que tal distintivo habría alcanzado con la disposición más usual en cualquier ángulo del lienzo. Completa ese ornato el tapete de la mesa con galón y flecadura dorada, así como un pesado cortinaje con borlas que unifica cromáticamente el fondo y concede un protagonismo mayor al individuo retratado.

La inclusión de dicho elemento sugiere que el pintor sevillano pudo recibir algún apunte más para su realización, ya que, por ejemplo, la disposición cruzada del ornato textil parece semejante a la concebida por Luis de la Cruz en el retrato previo de Cristóbal Bencomo (Figura 3). Tal vínculo nos permite diferenciar los procedimientos recurridos por uno y otro pintor en tan poco tiempo, aunque ese hecho se antoja fundamental para la unidad procurada a los retratos del aula capitular desde 1819. Si el lienzo del artista insular abogaba por la corrección formal a través del dibujo y una técnica precisa, la creación de Domínguez Bécquer llamó la atención por todo lo contrario: la soltura que manifiesta un manejo hábil del pincel y la aplicación libre del color en tonos que contrastan abiertamente a través de una gama reducida con vivos verdes, grises y rojos. No olvidemos que así lo hizo notar Antonio Pacheco en una misiva enviada a Juan José García durante 1835, donde señalaba que la pincelada le había complacido mucho o que el resto de capitulares quedaron satisfechos por su buena ejecución ${ }^{53}$.

Los adelantos en el apartado técnico son mucho más evidentes al establecer comparaciones entre el retrato que nos ocupa y los modestos trabajos de Juan de Abreu, aun cuando todos arrojen una cronología próxima. Sin embargo, dicha forma de pintar no impidió que el artista sevillano recreara con detalle algunos componentes de la obra, destacando, entre otros, las piezas ya aludidas de pedrería o los documentos que recuerdan la actividad acometida por Román y Linares antes de 1824. En este sentido no debe obviarse que, por ejemplo, la bula fundacional recreada muestra grandes semejanzas con el manuscrito original al imitar los motivos de tinta negra sobre el pergamino de vitela y el escudo de plomo que cuelga de un lateral, identificando a Pío VII en calidad de pontífice que le dio curso legal en febrero de 1819, y no en 1818 como señala Domínguez Bécquer (Figuras 4-5). Lo mismo cabría decir del real decreto auxiliatorio, sobre el que descansa la otra mano del prelado (Figura 6).

${ }^{53}$ B.U.L.L., Fondo Antiguo, Ms. 27-II, f. 101r; y A.C.L.L., Libro VIII de actas capitulares, f. 191v (junta de 31-7-1835). 
La verosimilitud podría aplicarse también al encaje de hilo que ribetea el roquete (Figura 7), a los textiles de la muceta con su habitual botonadura roja y, sobre todo, a los rasgos fisonómicos, porque, como escribía Pacheco al tiempo de la recepción, "todos convienen unánimes en que se le parece bastante" ${ }^{54}$. No sería extraño, por lo tanto, que el modelo posara para el artista en más de una ocasión, quizá en sesiones periódicas y no regladas como era costumbre durante aquella época. Ese trámite supuso un esfuerzo para el anciano Román y Linares, quien, como ya sabemos, en diciembre de 1834 expresaba su disposición para ello sin olvidar "la repugnancia que siempre he tenido a prestarme" 55 .

El encargo del cabildo lagunero no debieron desaprovecharlo el eclesiástico o familiares próximos para obtener otra imagen suya, protocolaria igualmente y afín a la remitida a Tenerife. Hay indicios de que al menos una más pudo pintarse entonces, a buen seguro como parte de la petición que él mismo y García hicieron a Domínguez Bécquer. Lamentablemente no se sabe nada sobre ella ni su paradero, pues tan solo conocemos una versión de mayor pobreza en el acabado técnico, tal vez copia de la que ahora suponemos perdida o sin identificar (Figura 8). Se trata de una pintura aparecida en el mercado del arte de Madrid como "retrato de cardenal", cuyo bajo importe no impidió que fuera vendida en octubre de $2011^{56}$. Al compararlo con la obra lagunera, no cabe duda de que la identidad del modelo corresponde con Vicente Román y que su anónimo artista, quizá un maestro secundario de Sevilla, recrearía el que estimamos ahora como segundo retrato de nuestro obispo en un formato menor ${ }^{57}$. Así lo avala el hecho de que la efigie no contenga emblemas alusivos a la diócesis nivariense -esencialmente la bula y el decreto previo, citados como requisitos figurativos por los canónigos de Tenerife- y sí los propios de un religioso con estatus episcopal, convencionales en todo y faltos de originalidad.

Aunque se manifiesta sentado en un sillón idéntico y muestra el mismo atuendo con roquete de encaje y muceta oscura, su pobre ejecución lo distancia del original o de la que suponemos segunda versión de Bécquer. Pese a ello, existe un interés latente por recrear otros elementos y enriquecer la composición con una librería al fondo o el Cristo Crucificado que se dispone sobre la mesa auxiliar en forzado escorzo. De resto, el tapete de tejido grueso con galón y flecadura,

${ }^{54}$ B.U.L.L., Fondo Antiguo, Ms. 27-II, f. 101r.

${ }_{55}$ B.U.L.L.. Fondo Antiguo, Ms. 27-II, f. 97r.

${ }^{56}$ Subastas Segre, lote 41, subasta 75 (octubre de 2011). Se catalogó entonces como "escuela española" del siglo XVIII. La existencia de esta obra nos fue comunicada entonces por los compañeros investigadores Ángel Muñiz Muñoz y Germán F. Rodríguez Cabrera.

${ }^{57}$ Las medidas de esta obra son 126,5 x $94 \mathrm{~cm}$, algo menos que el ejemplar catedralicio. Agradecemos la información sobre ella a Mercedes de Miguel y José Luis Requena, responsables de Subastas Segre. 
el cortinaje verde que cierra la composición o el adorno del sillón con fina talla no pueden negar su vínculo con la efigie que estudiamos de Canarias (Figura 1).

\section{EL RETRATISTA}

En la capacidad de reproducir fielmente el semblante de los personajes que posaron ante su caballete radica el éxito de Domínguez Bécquer como retratista, puesto que la crítica contemporánea reconoció siempre tal condición. Así, por ejemplo, en las páginas de la revista sevillana El Paraíso un redactor señalaba en 1838 que sus retratos evidenciaban "exacto parecido y mucha corrección en el dibujo" 58 . Intelectuales de la época expresaron la misma idea, porque, entre otros, Julián Williams informaba al acuarelista David Roberts (1796-1864) que durante 1834 Bécquer había concluido "muchos y buenos retratos dentro de su estilo, aunque más grandes diría yo, de medio cuerpo". Apostillaba luego que "algunos son excelentes" $" 59$, por lo que deducimos que en los años siguientes sería ya una referencia ineludible para el panorama artístico local. A ello contribuyeron circunstancias muy diversas, algunas vinculadas con la difusión que Bécquer hizo del tipismo andaluz con un criterio afín al seguido por maestros coetáneos ${ }^{60} \mathrm{y}$ el continuismo procurado a una actividad regular y uniforme en lo formal. Sea como fuere, su progreso se vio favorecido con la marcha conjunta a Madrid de los pintores Antonio Esquivel (1806-1857) y José Gutiérrez de la Vega (1791-1865), de modo que a partir de 1831 fue uno de los más notables de cuantos residieron y trabajaron con regularidad en Sevilla ${ }^{61}$.

El interés que suscita la pintura andaluza del Romanticismo con nuevos fundamentos de análisis ${ }^{62}$ y las cualidades perceptibles en ciertas obras confirman la dedicación de José María Domínguez Bécquer al retrato, ensombrecida siempre por su actividad como autor costumbrista para atender una demanda creciente en España e Inglaterra. Tal y como sugiere Rubio Jiménez, la notoriedad que el pintor reveló en esa faceta creativa es un hecho constatado cuando mediaba la

${ }^{58}$ REINA PALAZÓN, Antonio: La pintura costumbrista en Sevilla (1830-1870). Sevilla, 1979, pp. 144-145.

59 GIMÉNEZ CRUZ, Antonio: La España pintoresca de David Roberts. El viaje y los grabados del pintor. Málaga, 2007, p. 312.

${ }^{60}$ MÉNDEZ RODRÍGUEZ, Luis: La imagen de Andalucía en el arte del siglo XIX. Sevilla, 2008, pp. 62-64

${ }^{61}$ Últimos comentarios al respecto en DE LA BANDA Y VARGAS, Antonio: Antonio María Esquivel. Sevilla, 2002, pp. 33-39.

${ }^{62}$ VALDIVIESO, Enrique: "Pintura y sociedad en la Sevilla romántica", El gnomo, boletín de estudios becquerianos, 2, 1993, pp. 135-142; y VALDIVIESO, Enrique y FERNÁNDEZ LÓPEZ, José: Pintura romántica sevillana. Sevilla, 2011. 
década de $1830^{63}$, al tiempo que Román y su sobrino Juan José García contrataron el lienzo que tratamos. En ello debió influir el encargo que la casa real hizo al artista de hasta once representaciones de la joven reina Isabel $\mathrm{II}^{64}$, por lo que es probable que la ausencia de Sevilla que ahora documentamos hasta diciembre de 1834 guarde relación con tal petición o encomienda.

Las limitaciones ya señaladas con que se concibió el retrato de Román permiten que no sea una obra crucial en el catálogo de Bécquer y muestre grandes diferencias con creaciones previas, entre ellas el retrato de un caballero extranjero que fue firmado en Sevilla durante 1834 y reapareció por último en el comercio de $\operatorname{arte}^{65}$. Más cercana es, sin embargo, la efigie privada del coleccionista y tertuliano inglés Julián Williams, ya citado, aunque en ella se advierte mayor calidad y espontaneidad al prescindir del carácter oficial o protocolario que tanto nos interesa ahora ${ }^{66}$; y lo mismo podría decirse del retrato de un caballero que Valdivieso dio a conocer años atrás, firmado en $1836^{67}$.

Lástima que la obra tinerfeña ofrezca una datación tan temprana y no sea descrita en el libro de cuentas que el pintor inició en 1837, indispensable para reconstruir la mecánica de trabajo impuesta en su taller y el alto volumen de clientes que acudían a él con el propósito de adquirir creaciones de todo tipo ${ }^{68}$. De acuerdo a los apuntes que contiene dicho cuaderno o manuscrito anotado, constatamos ahora que los 600 pesos invertidos por los integrantes del Cabildo de La Laguna no fueron una suma elevada si atendemos a las cualidades plásticas de la efigie de Román, a la técnica recurrida en ella y al tamaño que alcanzó el lienzo por recomendación suya con dimensiones extremas de 148 x $103 \mathrm{~cm}$. Además, podría ponerse en relación con el ingente número de retratos que ejecutó durante esos años al óleo, los cuadros costumbristas de gabinete, las muchas miniaturas que tanto éxito alcanzaron desde entonces, los "figurines" en acuarela o aguada sobre papel, y las copias de creaciones previas por deseo expreso de los

${ }^{63}$ RUBIO JIMÉNEZ, J.: José María..., op. cit., p. 122.

${ }^{64}$ Documentado por una carta que Julián Williams escribió a David Roberts en septiembre de 1834. GIMÉNEZ CRUZ, A.: La España pintoresca..., op. cit., p. 312.

${ }^{65}$ Estudiado por PIÑARES, Manuel: Pintura antigua del siglo XIX. Madrid, 2004, pp. 46-48; y RUBIO JIMÉNEZ, J.: José María..., op. cit., lám. 3, s. p.

${ }^{66}$ RUBIO JIMÉNEZ, J.: José María..., op. cit., lám. 2, s. p.

${ }^{67}$ VALDIVIESO, Enrique: Pintura sevillana del siglo XIX. Sevilla, 1981, p. 32, fig. 26.

${ }^{68}$ A pesar de las citas o apuntes previos, dicho documento fue publicado por ROMERO TOBAR, Leonardo (ed.): Autógrafos juveniles (Manuscrito 22.511 de la Biblioteca Nacinal). Barcelona, 1993. Para una valoración de los dibujos que contiene y las anotaciones que Valeriano Domínguez Bécquer (1833-1870) y Gustavo Adolfo Bécquer (1836-1870) hicieron en dicho documento tras la muerte de su padre en 1841, resulta indispensable la consulta de RUBIO JIMÉNEZ, Jesús: Pintura y literatura en Gustavo Adolfo Bécquer. Sevilla, 2006. 
comitentes $^{69}$. Todo ello no hace más que incidir en la buena elección que Román y sus allegados realizaron entre los artistas de Sevilla, porque, tal y como prevenían en diciembre de 1834, "el maestro es de lo mejor". De este modo, la catedral de La Laguna pudo contar desde sus inicios con una pintura estimable y de buena factura, a buen seguro la más sobresaliente de cuantas integran su galería de retratos a día de hoy.

\section{APÉNDICE DOCUMENTAL}

Recibo del retrato de Vicente Román y Linares.

B.U.L.L., Fondo Antiguo, Ms. 27-II, f. 100r.

"Cuenta que se remite al Illmo. Cabildo de la Sta. Iglesia de Tenerife, de los gastos ocurridos en hacer y conducir hasta Cádiz el retrato del Iltmo. Sor. D. ${ }^{\mathrm{n}}$ Vicente Román y linares, Obispo Auxiliar que fué de Tenerife.

Por el Retrato... 600

Por el marco dorado... 146

Por el caxón para la conducion del retrato... 60

Por el ule para cubrir el caxón... 80

Por la conducion de Sevilla á Cadiz en el Vapór Betis... 37

Entregádo á $\mathrm{D}^{\mathrm{n}}$ Santiago Montemayor, encargado de la conducion del

Retrato, para atendér á los gástos que ocurran desde Cádiz a Tenerife... 60

Importe total... 983

Sevilla, 1. ${ }^{\circ}$ de Julio de 1835.

Juan José García

Añádense á los anteriores gastos, los siguientes.

Por el fléte de Cádiz á Santa Cruz... 80

Capa el $1 / 0$ por $\%$... 8

Lancha, y condución á la Ciudad... 4

Embarque del vapor á la Antoñita... 10

Desembarque al muelle de Santa Cruz... 10

Condución á la Laguna... 05

Argollas de hierro para colgarlo... 10

Total... 127

A[ntonio]. P[ereira]. P[acheco]. y R[uiz].»

Fecha de recepción: 30 de septiembre de 2016

Fecha de aceptación: 19 de enero de 2017

${ }^{69}$ RUBIO JIMÉNEZ, J.: José María..., op. cit., pp. 124-128. 


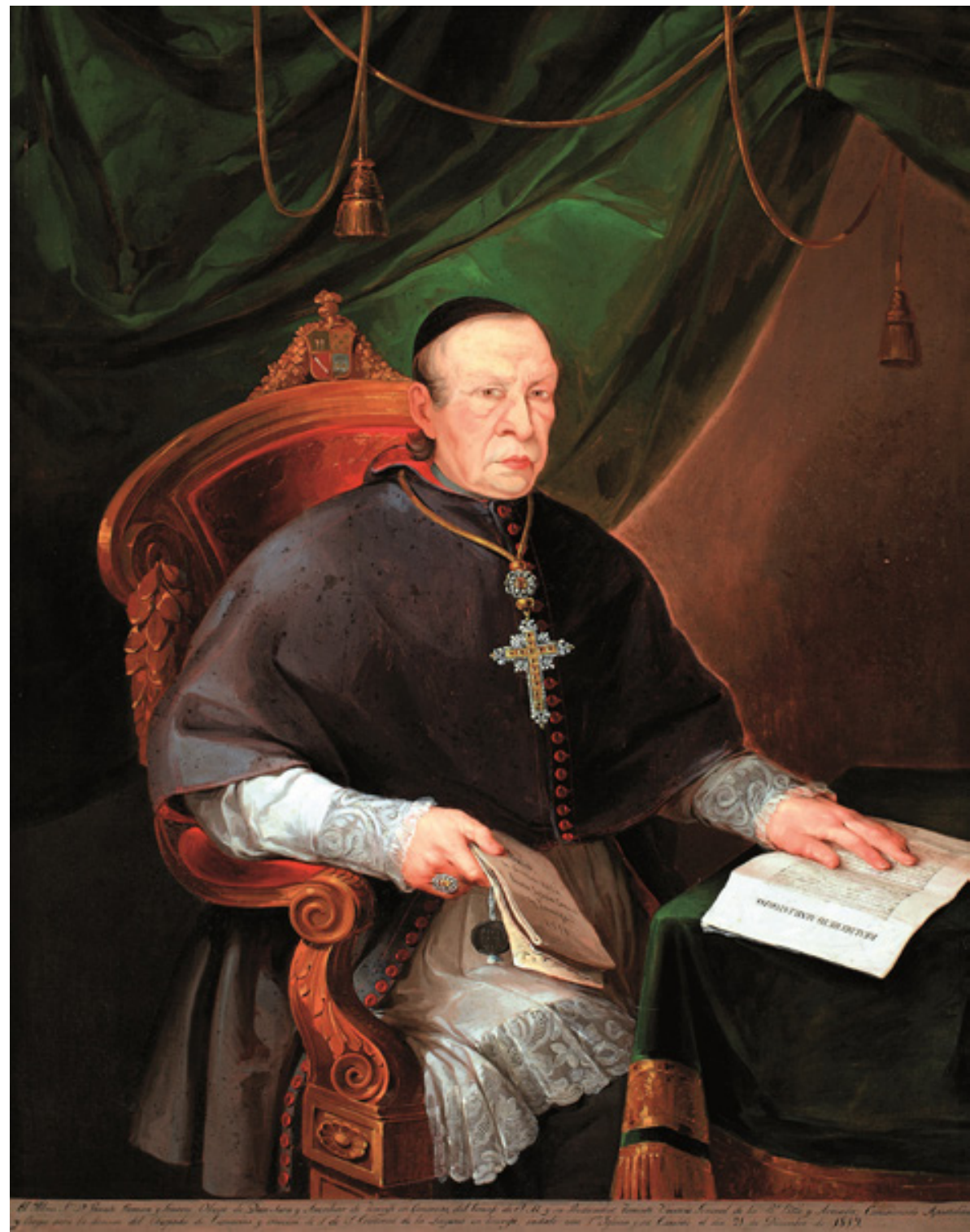

Figura 1. José Domínguez Bécquer, Vicente Román y Linares, catedral de La Laguna. Foto: Fernando Cova del Pino. 


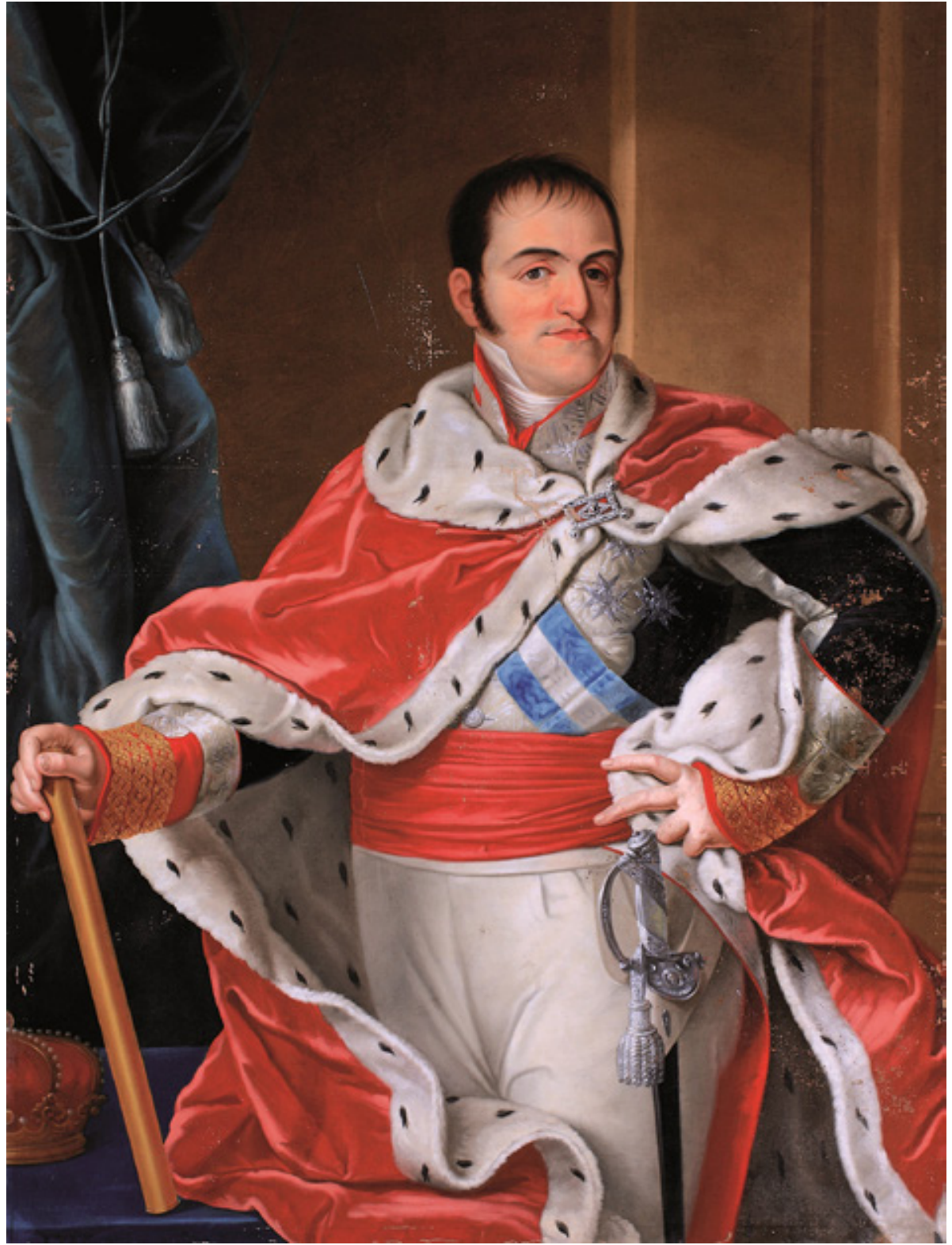

Figura 2. Luis de la Cruz y Ríos, Fernando VII, catedral de La Laguna. Foto: Fernando Cova del Pino. 


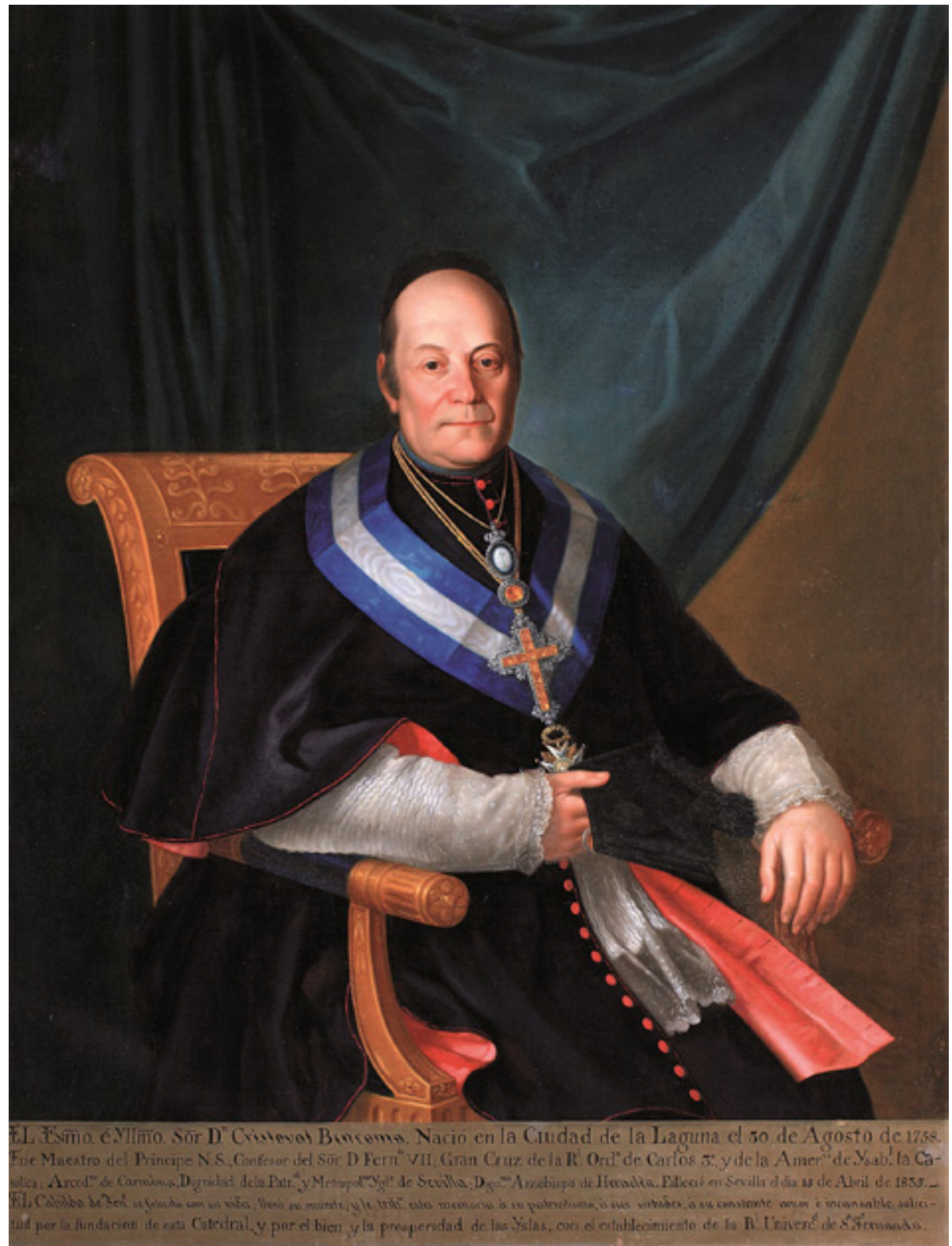

Figura 3. Luis de la Cruz y Ríos, Cristóbal Bencomo, catedral de La Laguna. Foto: Fernando Cova del Pino. 


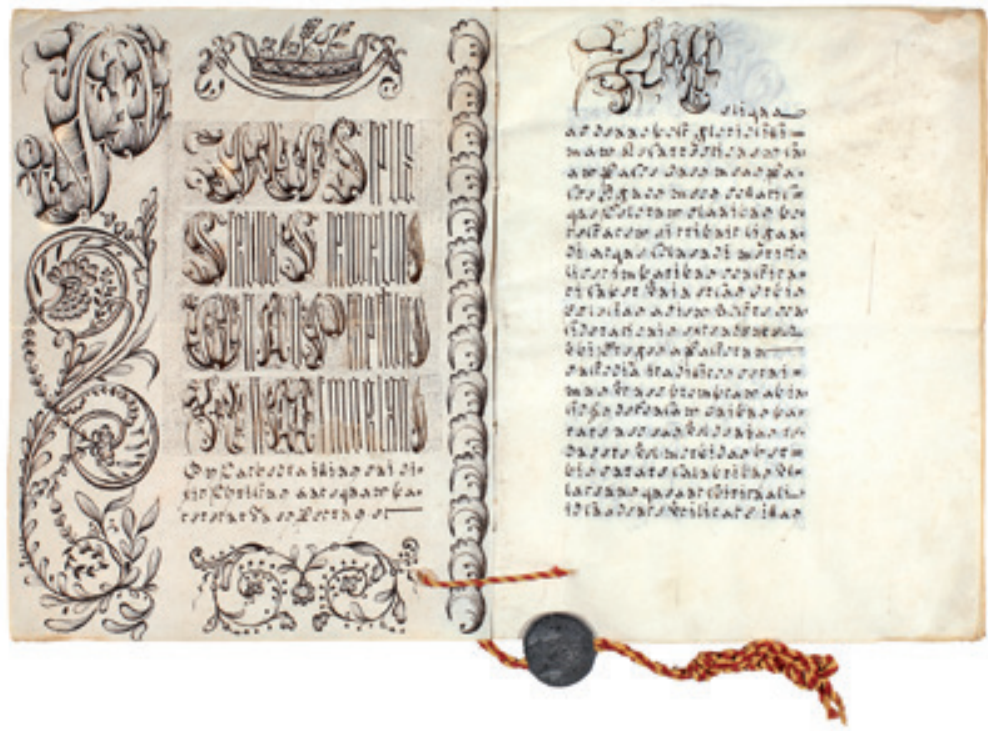

Figura 4. Bula fundacional de la diócesis nivariense, Archivo de la catedral de La Laguna. Foto: Fernando Cova del Pino.

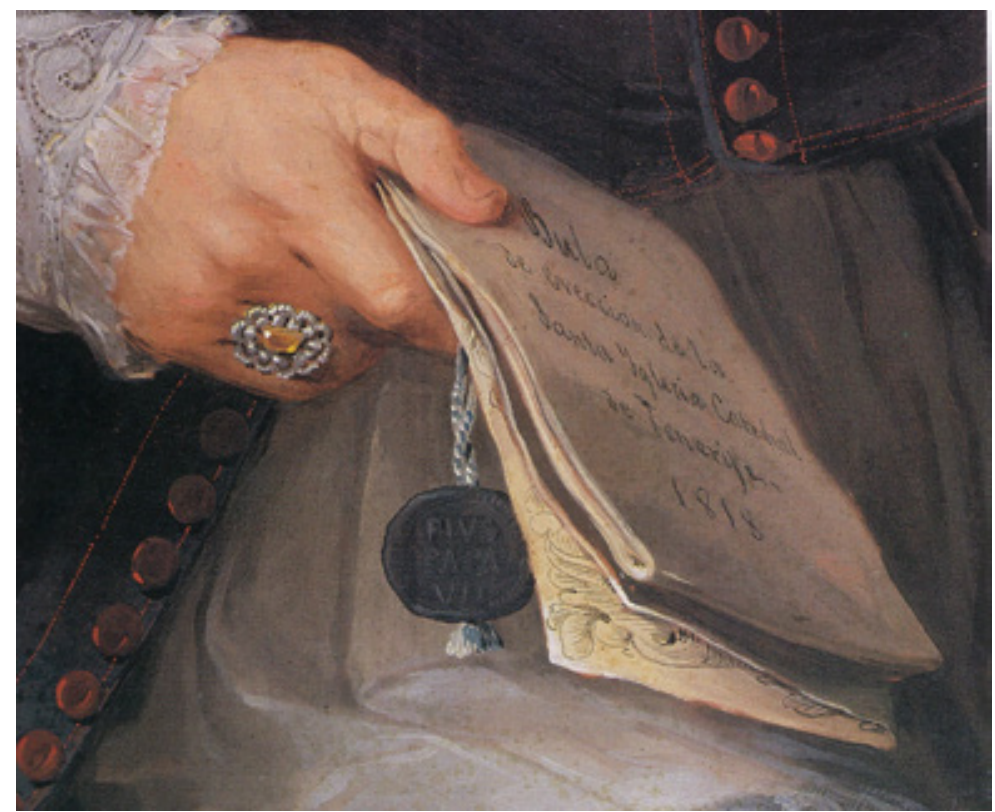

Figura 5. José Domínguez Bécquer, Vicente Román y Linares (detalle), catedral de La Laguna. Foto: Juan Alejandro Lorenzo. 


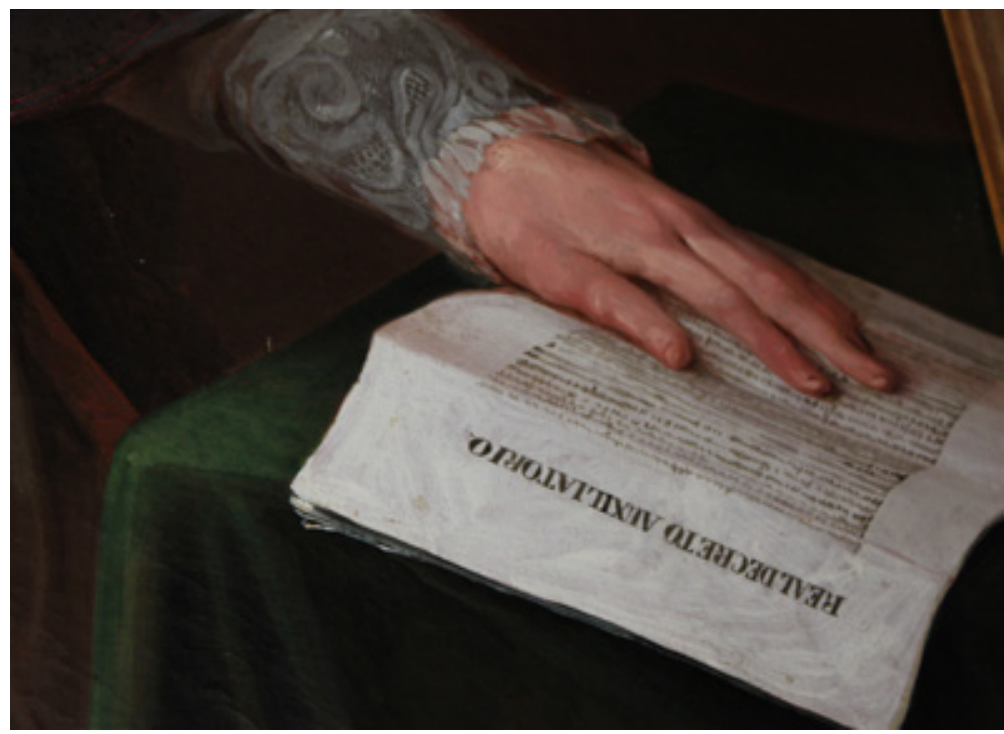

Figura 6. José Domínguez Bécquer, Vicente Román y Linares (detalle), catedral de La Laguna. Foto: Juan Alejandro Lorenzo.

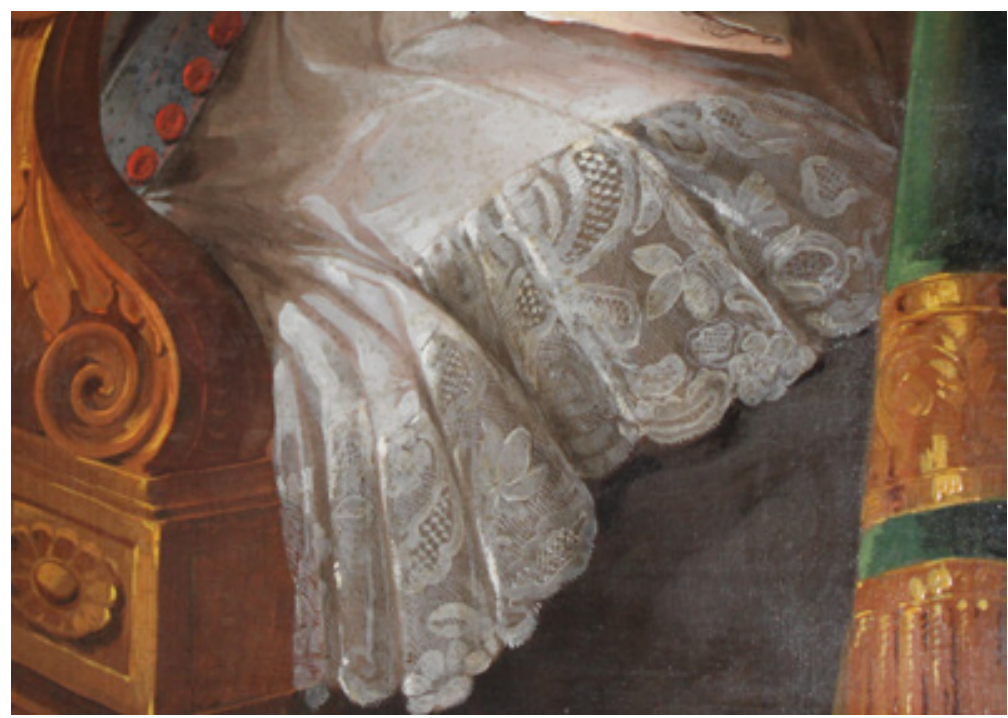

Figura 7. José Domínguez Bécquer, Vicente Román y Linares (detalle), catedral de La Laguna. Foto: Juan Alejandro Lorenzo. 


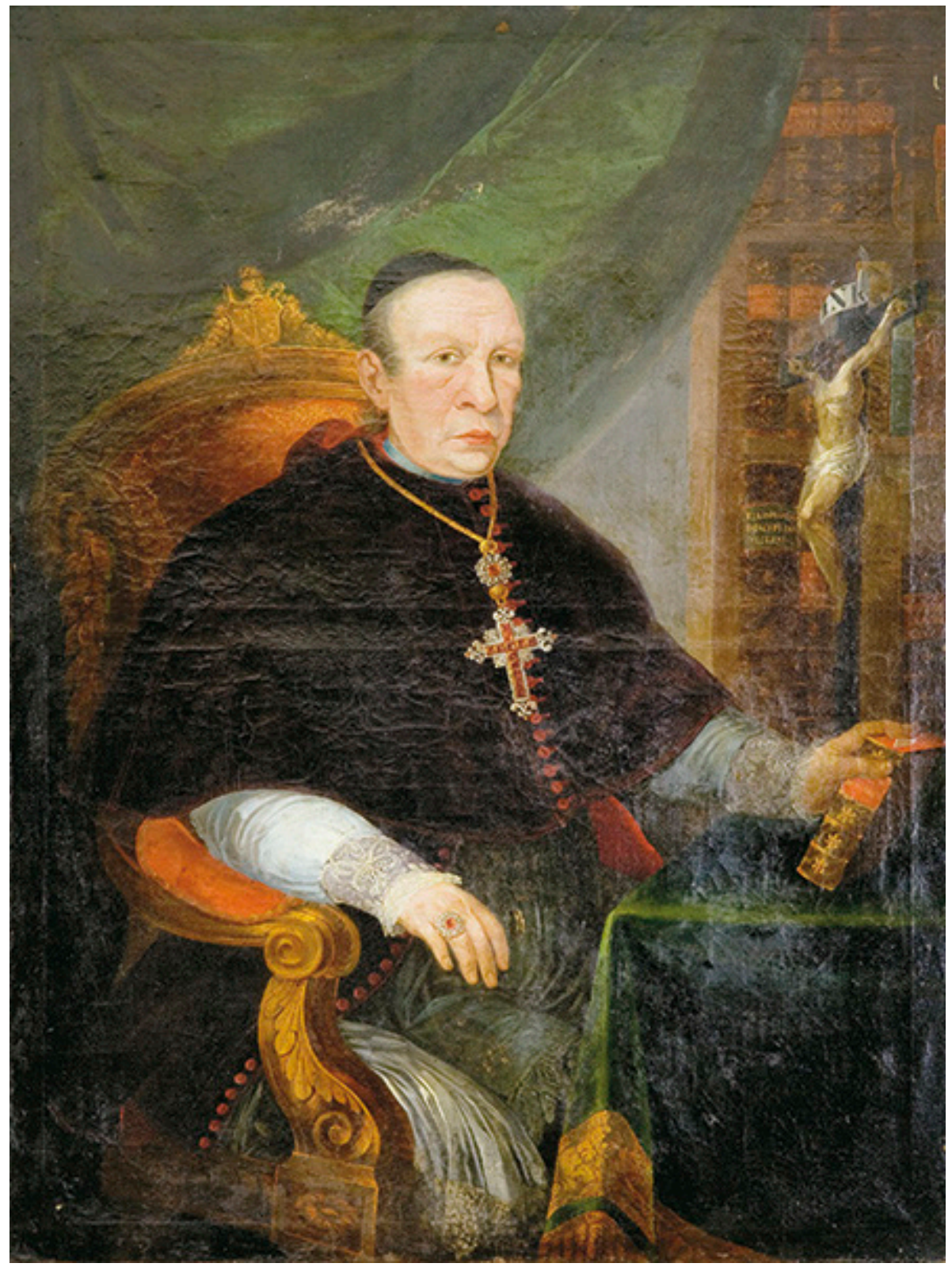

Figura 8. Anónimo, Vicente Román y Linares, colección particular, Madrid. Foto: Subastas Segre. 